\title{
Observations of new particle formation in enhanced UV irradiance zones near cumulus clouds
}

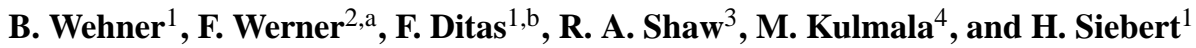 \\ ${ }^{1}$ Leibniz Institute for Tropospheric Research (TROPOS), 04318 Leipzig, Germany \\ ${ }^{2}$ Leipzig Institute for Meteorology, 04103 Leipzig, Germany \\ ${ }^{3}$ Department of Physics, Michigan Technological University, Houghton, Michigan, USA \\ ${ }^{4}$ Department of Physics, University of Helsinki, P.O. Box 64, 00014 Helsinki, Finland \\ ${ }^{a}$ now at: Joint Center for Earth Systems Technology (JCET), Physics Department, Baltimore, Maryland, USA \\ b now at: Max Planck Institute for Chemistry, 55128 Mainz, Germany
}

Correspondence to: B. Wehner (birgit@tropos.de)

Received: 10 April 2015 - Published in Atmos. Chem. Phys. Discuss.: 29 April 2015

Revised: 7 October 2015 - Accepted: 7 October 2015 - Published: 21 October 2015

\begin{abstract}
During the CARRIBA (Cloud, Aerosol, Radiation and tuRbulence in the trade wInd regime over BArbados) campaign, the interaction between aerosol particles and cloud microphysical properties was investigated in detail, which also includes the influence of clouds on the aerosol formation. During two intensive campaigns in 2010 and 2011, helicopter-borne measurement flights were performed to investigate the thermodynamic, turbulent, microphysical, and radiative properties of trade-wind cumuli over Barbados. During these flights, 91 cases with increased aerosol particle number concentrations near clouds were detected. The majority of these cases are also correlated with enhanced irradiance in the ultraviolet (UV) spectral wavelength range. This enhancement reaches values up to a factor of 3.3 greater compared to background values. Thus, cloud boundaries provide a perfect environment for the production of precursor gases for new particle formation. Another feature of cloud edges is an increased turbulence, which may also enhance nucleation and particle growth. The observed events have a mean length of $100 \mathrm{~m}$, corresponding to a lifetime of less than $300 \mathrm{~s}$. This implies that particles with diameters of at least $7 \mathrm{~nm}$ grew several nanometers per minute, which corresponds to the upper end of values in the literature (Kulmala et al., 2004). Such high values cannot be explained by sulfuric acid alone; thus extremely low volatility organic compounds (ELVOCs) are probably involved here.
\end{abstract}

\section{Introduction}

The influence of the number concentration of available cloud condensation nuclei $(\mathrm{CCN})$ on the number concentration of cloud droplets was shown for the first time in Warner and Twomey (1967). They demonstrated that smoke from sugar cane fires leads to a significant increase in the number of cloud droplets. Furthermore, a change in $\mathrm{CCN}$ followed by a change in the cloud droplet number size distribution leads to a change in the shortwave albedo of clouds (Twomey, 1977). Since these first studies the influence of the availability of aerosol particles on the microphysical properties of clouds has been investigated many times. On the other hand, clouds strongly influence the incoming solar radiation, and thus they may also influence the formation and distribution of aerosol particles, e.g., by new particle formation (NPF; Birmili and Wiedensohler, 2000).

Identifying the origin of ultrafine aerosol particles (smaller than $20 \mathrm{~nm}$ ) in the remote marine atmosphere has been an objective since the 1990s. NPF requires not only low particle surface area concentration but also a sufficient concentration of potential precursor gases. Covert et al. (1992) observed an increase in the number concentration of small particles accompanied by a decrease in the surface area concentration in the marine boundary layer. Shaw (1989) concludes that, for clean environments, the role of clouds has to be taken into account due to the photochemical production of $\mathrm{SO}_{4}^{2-}$ as well as the cleansing effect that lowers the aerosol particle surface concentration. 
Several studies from the 1990s show increased particle concentrations near the top and outflow of individual marine cumulus clouds (e.g., Clarke et al., 1997, 1998; Perry and Hobbs, 1994). Radke and Hobbs (1991) found regions with high relative humidity around cumulus clouds and increased particle concentrations therein. These regions coincide with regions of increased turbulence. Results from Keil and Wendisch (2001) suggest that this phenomenon happens not only in the marine environment but also at tops of continental clouds, where they found peaks of ultrafine particles at stratocumulus cloud tops over Germany. Garrett et al. (2002) observed a high number concentration of aerosol particles $<100 \mathrm{~nm}$ at tops of stratiform clouds in the Arctic. Saxena and Grovenstein (1994) observed an increase in CCN concentration within such clouds, which demonstrates the influence of clouds on the aerosol distribution. A model study done by Hegg (1991) demonstrated that bimolecular nucleation within clouds is a viable mechanism for the particle production. Weber et al. (2001) observed regions of increased ultrafine particle number concentrations near a marine frontal cloud in a height of approximately $6 \mathrm{~km}$. Here, the nucleation was observed in $60 \mathrm{~km}$ wide bands with enhanced intensity of upwelling shortwave radiation.

The results of these previous studies were obtained by aircraft measurements equipped with commercial condensation particle counters (CPCs). The observed events had a horizontal extent of approximately $1 \mathrm{~km}$ or more, and shorter events were not discussed due to limitations in the experimental setup. One commonly used aircraft, the C-130, was operated at an average speed of about $100 \mathrm{~m} \mathrm{~s}^{-1}$. Typical CPCs with a temporal resolution of approximately $1 \mathrm{~s}$ therefore allow for detection of events with a length of $\sim 200 \mathrm{~m}$.

This study presents results from the CARRIBA (Cloud, Aerosol, Radiation and tuRbulence in the trade wInd regime over BArbados) campaign using two helicopter-borne measurement platforms that simultaneously sampled basic meteorological parameters, in situ cloud microphysical and aerosol variables, and cloud-reflected spectral radiation. The advantage of these helicopter-borne measurements is the low true air speed of $20 \mathrm{~m} \mathrm{~s}^{-1}$ combined with a high temporal resolution. The observed data from 28 measurement flights were obtained in the marine boundary layer and the cloud layer, where 91 individual cases of NPF were found. Besides providing an investigation in a new geographic environment, these measurements were made with very high spatial resolution (approximately $20 \mathrm{~m}$ ) and with a lower size limit of $6 \mathrm{~nm}$ for aerosol detection. This allows for investigation of statistical properties of the NPF events and their correlation with meteorological, microphysical, and radiation variables. An introduction to the CARRIBA project and the scientific goal are given in Siebert et al. (2013).

\section{The CARRIBA measurement campaign}

The CARRIBA campaign was performed in November 2010 and April 2011 near the island of Barbados in the Caribbean Sea. One major objective of CARRIBA was to investigate the influence of aerosol particles on the formation and life cycle of trade-wind cumuli. Basic meteorological variables, as well as turbulence, aerosol, and in situ cloud microphysical parameters, were measured by the Airborne Cloud Turbulence Observation System (ACTOS) payload. Collocated observations of upward spectral radiances and irradiances have been collected by the Spectral Modular Airborne Radiation measurements sysTem for HELIcopter-borne ObservationS (SMART-HELIOS). Both payloads were attached to the helicopter by means of a $160 \mathrm{~m}$ long rope. These measurements were supplemented by ground-based measurements at the eastern most tip of Barbados at the Ragged Point station. There, dust measurements have been performed continuously since 1964 by the University of Miami (e.g., Li-Jones and Prospero, 1998) and several systems for thorough groundbased aerosol characterization were additionally deployed for CARRIBA. The second ground-based site contains various remote sensing instruments measuring basic aerosol and cloud parameters over several years and is operated by the Max Planck Institute for Meteorology (MPI-M) in Hamburg, Germany (Nuijens et al., 2014).

Measurement flights of ACTOS started with a vertical profile up to 2 to $3 \mathrm{~km}$ above sea level between two predefined navigation points over the ocean off the east coast of Barbados. After this profile, flights usually continued with the cloud sampling strategy depending on local cloud conditions. More details about CARRIBA as well as meteorological conditions and examples of flight tracks are given in Siebert et al. (2013).

\section{Instrumentation}

\subsection{The ACTOS measurement platform}

The helicopter-borne measurement payload ACTOS was used to perform measurements with high temporal and spatial resolution within the marine boundary layer up to a height of $\approx 3000 \mathrm{~m}$ above sea level. ACTOS is an autonomous system that is attached to a helicopter and flown with a true airspeed of about $20 \mathrm{~m} \mathrm{~s}^{-1}$ to ensure measurements are safely outside of the helicopter's downwash (Siebert et al., 2006). The payload is equipped with fast sensors for measuring the three-dimensional wind vector, temperature, static pressure, and humidity. A navigation unit provides attitude angles, position, and velocity vector components to transfer the wind measurements into an Earth-fixed coordinate system. In addition to the meteorological standard parameters, cloud microphysical properties such as liq- 
uid water content (LWC), and cloud droplet size distribution are measured during cloudy conditions.

A real-time data acquisition system and independent power unit complete ACTOS. A telemetry link to the helicopter ensures online monitoring of basic parameters during the flight. One scientist is onboard to fine-tune the flight pattern with regard to the observed cloud situation. In this study all time series are given in seconds of day (SOD) in UTC.

\subsection{Aerosol measurements on ACTOS}

Additional instrumentation to measure aerosol particle number size distributions (NSDs) between $6 \mathrm{~nm}$ and $2.5 \mu \mathrm{m}$, as well as the total particle number concentration $(N)$, was installed on ACTOS during CARRIBA. A common inlet was used for all aerosol measurements, leading the sample flow through a diffusion dryer to ensure dry measurement conditions ( $<50 \%$ relative humidity). Afterwards, a flow splitter divides the flow line into four lines for the individual instruments. These instruments include a total condensation particle counter (CPC; model 3762A, TSI Inc., St. Paul, MN, USA), a scanning mobility particle sizer (SMPS), and an optical particle counter (OPC; model 1.129, Grimm Aerosol Technik, Ainring, Germany). The SMPS system was built at TROPOS and mainly consists of a Kr-85 neutralizer (model 3077A, TSI Inc.), a Hauke-type differential mobility analyzer (short version), and a CPC (model 3762A, TSI Inc.). This system was optimized in terms of weight and power consumption for operation on ACTOS. The SMPS measures aerosol particle number size distributions from 6 to $250 \mathrm{~nm}$ with a temporal resolution of $120 \mathrm{~s}$. The OPC measures particle number size distributions from $250 \mathrm{~nm}$ to $2.5 \mu \mathrm{m}$ with a temporal resolution of $1 \mathrm{~s}$. Therefore the combination of both instruments provides aerosol number size distributions from $6 \mathrm{~nm}$ to $2.5 \mu \mathrm{m}$ using the inversion described by Pfeifer et al. (2014). SMPS measurements have been corrected for variations in the volume flow due to pressure changes during the flight and also for diffusion losses within the inlet line. The CPC measures the total particle number concentration $\left(N_{\mathrm{CPC}}\right)$ with particle diameter $D_{\mathrm{p}}>6 \mathrm{~nm}$ and a temporal resolution of $1 \mathrm{~s}$. This instrumentation was introduced in Wehner et al. (2010). The measured aerosol parameters were all corrected for standard temperature $\left(T_{0}=288 \mathrm{~K}\right)$ and pressure $\left(p_{0}=1013.15 \mathrm{hPa}\right)$.

In addition, the recently developed Fast CPC (FCPC) (Wehner et al., 2011) has been implemented on ACTOS and was used to measure the total particle number concentration $\left(N_{\text {FCPC }}\right)$ of aerosol particles $>7 \mathrm{~nm}$ with a temporal resolution of $\approx 10 \mathrm{~Hz}$. The FCPC has its own inlet on ACTOS, which is operated with a higher flow to minimize the residence time between inlet and FCPC.

While the FCPC has been tested intensively on the ground (Wehner et al., 2011), the CARRIBA campaigns were the first application for airborne measurements. The TSI CPC was used as a reference during periods with relatively con-

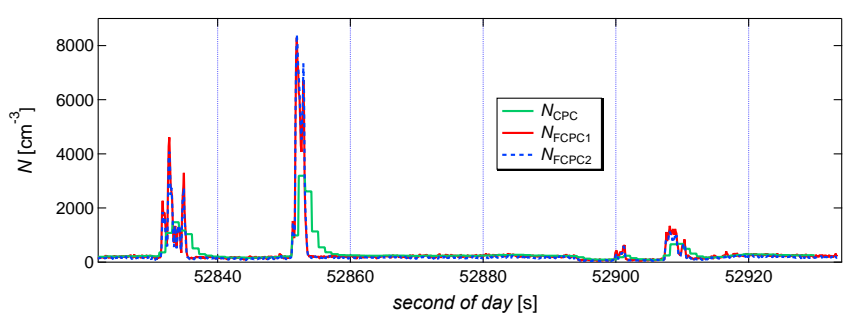

Figure 1. Time series of the two FCPC (FCPC1 and FCPC2) and the TSI CPC measured during a flight section on 22 April 2011.

stant $N$ to compare the FCPC in terms of long-term stability. During the two campaigns no systematic deviation between the two instruments was observed. During two flights of the first campaign in November 2010, technical problems occurred; those data have been excluded from this study. In preparation for the second campaign in 2011, the FCPC was improved and a second one was additionally installed on ACTOS. Thus, for the flights in April 2011, data from two FCPCs are available. Here, both instruments worked well and observed particle number concentrations from the two instruments agree within an uncertainty of $\pm 10 \%$.

Figure 1 shows a time series of $N_{\text {FCPC }}$ and $N_{\text {CPC }}$ on 22 April 2011 at cloud level. The background concentration during this flight varied between 150 and $250 \mathrm{~cm}^{-3}$ but individual events show particle number concentrations of more than $8000 \mathrm{~cm}^{-3}$. These events are detected by all three instruments, but the TSI CPC, with its lower time resolution, is not able to capture the maximum concentration measured by the FCPC. Moreover, the small-scale structure is resolved by the two FCPCs only. The time series demonstrates nicely how well both FCPCs agree, and in the following figures only data from FCPC1 will be shown.

\subsection{Radiation measurements using SMART-HELIOS}

Instrumentation to sample upward spectral irradiances $F_{\lambda}^{\uparrow}$ and cloud-reflected spectral radiances $I_{\lambda}^{\uparrow}$ was installed on SMART-HELIOS. Measurements performed with SMARTHELIOS are reported in Werner et al. (2013) and Werner et al. (2014). Optical fibers connect each of the two optical inlets to two respective grating spectrometers. These cover the wavelength $\lambda$ range between 180 and $1000 \mathrm{~nm}$ in the visible to near-infrared spectral wavelength range (VNIR) and between 900 and $2200 \mathrm{~nm}$ in the shortwave-infrared spectral wavelength range (SWIR). In the VNIR the spectrometers have a spectral resolution, defined by full width at half maximum, of $2-3 \mathrm{~nm}$; in the SWIR this is $8-9 \mathrm{~nm}$. The temporal resolution of sampled $F_{\lambda}^{\uparrow}$ and $I_{\lambda}^{\uparrow}$ is $0.1-0.3 \mathrm{~s}$. The field of view of the radiance inlet is $2^{\circ}$, resulting in a footprint $2.5 \mathrm{~m}$ in the cross-track and $4.2-8.5 \mathrm{~m}$ in the along-track direction (depending on the flight level above cloud top and the integration time of the sample). The optical inlets and spectrometers are calibrated with certified calibration standards 
traceable to the National Institute of Standards and Technology (NIST). The uncertainties in the $F_{\lambda}^{\uparrow}$ and $I_{\lambda}^{\uparrow}$ signals arise from uncertainties introduced during the radiometric calibration, as well as uncertainties in the calibration standards and the spectrometer signal, and are estimated to be $\pm 6 \%$ in the VNIR and $\pm 10 \%$ in the SWIR (Werner et al., 2013).

\section{Results}

For the CARRIBA campaigns, the measured particle number concentration in the marine boundary and cloud layer, excluding NPF events, was usually $\approx 100-300 \mathrm{~cm}^{-3}$ for the analyzed flights. During several flights, short events of increased particle number concentrations with maximum values of up to $17000 \mathrm{~cm}^{-3}$ were observed. In this study, events with a maximum number concentration of more than $1000 \mathrm{~cm}^{-3}$ were considered to be NPF events. This threshold was arbitrarily chosen but exceeds the background value by more than a factor of 3 . Furthermore, subsequent maxima were considered to be the same event if the concentration decreased to the background value for less than $2 \mathrm{~s}$ (or $40 \mathrm{~m}$ ); otherwise they were counted as individual events. Using these criteria, 91 events were detected in the cloud layer during measurements flights with valid FCPC data. The hypothesis is that these particles were formed by nucleation and grew to detectable sizes within the lifetime of the individual cloud sampled. Thus, these events will be called NPF events. Interestingly, almost all of the NPF events were observed in the vicinity of clouds. We did not find any dependence on orientation, flight direction, or upwind versus downwind direction relative to the cloud. Theoretically, such particles can also be artifacts, created by droplet fragmentation at the inlet (Weber et al., 1998; Craig et al., 2013). In our case with a true airspeed of $20 \mathrm{~m} \mathrm{~s}^{-1}$, aerodynamic breakup will not occur, and impaction breakup would occur only for cloud droplets larger than approximately $26 \mu \mathrm{m}$ in diameter. Most of the cloud droplets observed during CARRIBA were smaller (Schmeissner et al., 2015), and thus breakup would not occur. Another aspect excluding such artifacts is that most of the events were observed out of clouds. Furthermore, two different inlets were used for the different CPCs, but all events were observed at both CPCs at the same time.

\subsection{New particle formation events: examples}

NPF events occurred at different locations relative to surrounding clouds. Figure 2 shows examples of observed NPF to illustrate the variety of cases. Some instances were found near cloud edges (at both upwind and downwind sides) or between clouds, where the decrease in LWC was closely connected with an increase in $N$ (see Fig. 2a and b). Increased particle concentrations were observed during entering and leaving clouds, which rules out the possibility of artificial particle production. Furthermore, increased values in
$N$ were found in the entrainment zone, i.e., in regions at the cloud edge where the LWC was nonzero but fluctuating (see Fig. 2c). Other cases like the one shown in Fig. $2 \mathrm{~d}$ seem to occur without the presence of a nearby cloud, although from the in situ measurements alone the possibility that these observations were performed above cloud top cannot be excluded. These four cases will be discussed later in more detail.

The examples shown in Fig. $2 \mathrm{a}-\mathrm{d}$ also demonstrate the different resolution of the two CPCs: the laminar-flow-type $\mathrm{CPC}$, with its time resolution of $1 \mathrm{~s}$, cannot resolve the smallest structures that can be measured by the FCPC. Thus, the maximum concentration also cannot be resolved by the CPC because the variations appear smoother in this instrument. Some of the events last only a few seconds, which is close to the detection limit of the CPC.

The events have been identified by a significant increase in the total particle number concentration; however, the events are too short to obtain a complete particle number size distribution for the respective period. Thus, we have to speculate about size and origin of these particles. There are no anthropogenic particle sources because the measured concentration of $\mathrm{CO}_{2}$ does not follow $N$ in any case. Since there are no other sources, the observed particles are very likely produced by NPF - i.e., they were formed by homogeneous nucleation from one or more condensable species and subsequently grew into detectable sizes.

Because the SMPS measures individual particle diameter ranges sequentially within a scan, even with limited time resolution these measurements can give insight into whether these particles occur mainly in the ultrafine particle size range. During some events the observed diameter from the SMPS was in the ultrafine particle range $(<20 \mathrm{~nm})$, and the number size distribution showed a maximum around this value. This was the case for the NPF event in Fig. 2c. The SMPS started a scan from $6 \mathrm{~nm}$ at SOD 52924, which is shown in Fig. 3 together with the following number size distribution without NPF. Around 20 s later, between SOD 52940 and 52950, the event was observed in $N_{\text {FCPC }}$, corresponding to a selected diameter in the SMPS between 10 and $20 \mathrm{~nm}$. One hundred and twenty seconds later, the SMPS reaches the upper end and measures at $230 \mathrm{~nm}$. Similar cases were observed a few more times, but never at larger diameters in the NSD. This finding confirms our hypothesis that the event of increased particle number concentrations is caused by the formation of ultrafine particles and that these cases are indeed NPF events. However, the presented NSD is only representative of one NPF event and different events might exhibit a different distribution. Furthermore, the maximum of the NSD does not show the real maximum of the NPF event, because the SMPS was measuring in a certain diameter range, defined by the measurement program. 


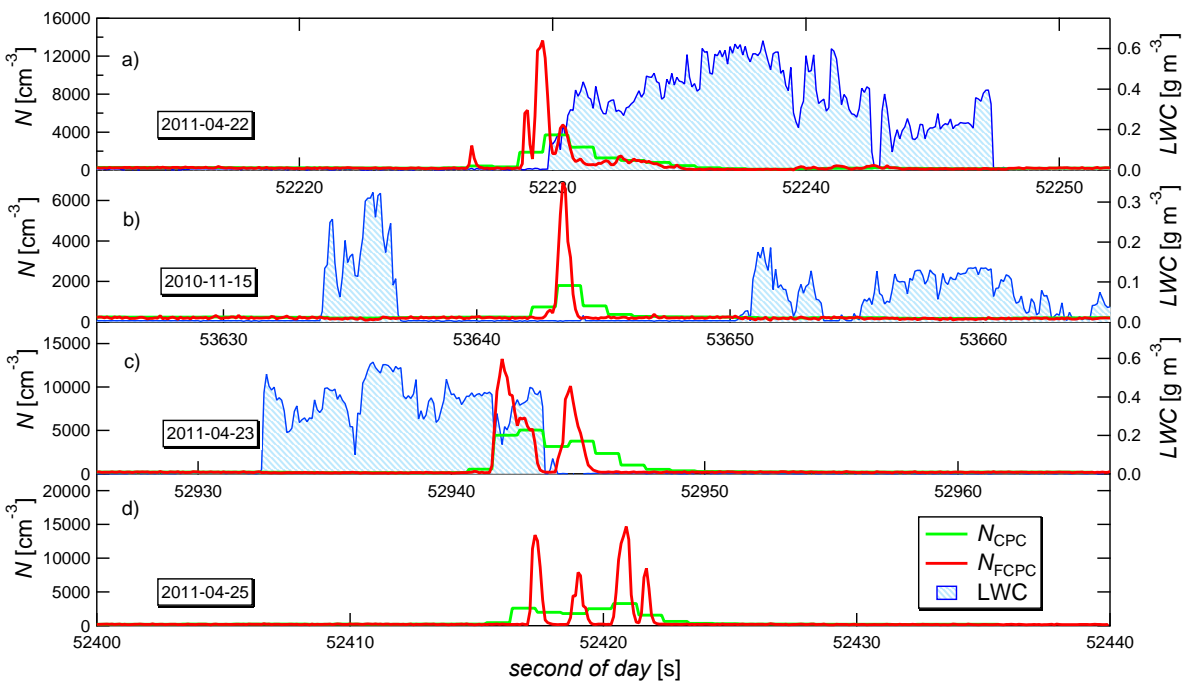

Figure 2. Time series of $N_{\mathrm{CPC}}, N_{\mathrm{FCPC}}$, and LWC over $40 \mathrm{~s}$ each during an event of increased particle number concentration (a) at a cloud edge, (b) between clouds, (c) in the entrainment region, and (d) without clouds nearby.

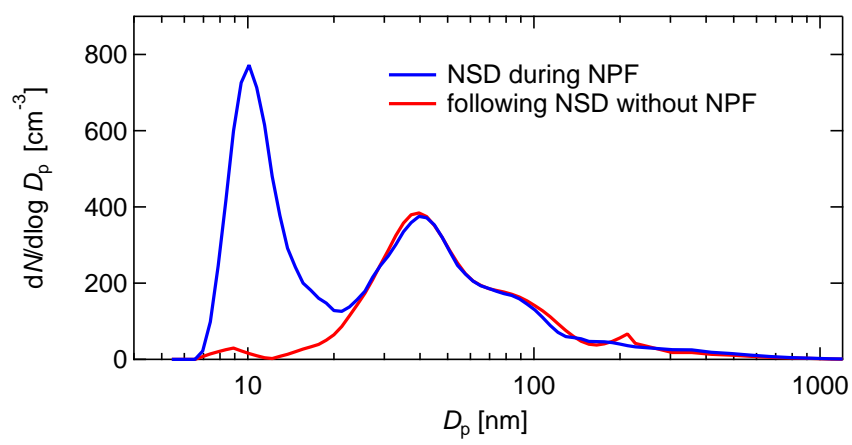

Figure 3. Number size distributions (NSD) measured on 23 April 2011, starting at SOD 52924 (cf. Fig. 2c).

\subsection{Statistics}

FCPC data from 28 flights are available. During 4 of those flights no NPF events were detected, and during 24 flights between 1 and 13 individual events were counted. This means that NPF events were observed during $83 \%$ of the investigated flights. Figure 4 shows the distribution of the horizontal extent of each individual event, assuming a constant flight speed of $20 \mathrm{~m} \mathrm{~s}^{-1}$. More than $50 \%$ of all events were observed to have a horizontal extent of less than $100 \mathrm{~m}$. This explains why they have rarely been observed during previous aircraft experiments. Such aircraft have a flight speed of at least $50-70 \mathrm{~m} \mathrm{~s}^{-1}$ (www.eufar.net), and most commercial CPCs in the past had a time resolution of $\geq 1 \mathrm{~s}$. Thus, events of increased number concentrations that cover a distance of $100 \mathrm{~m}$ or less could not be resolved with these systems.

Figure 5 shows the distribution of maximum particle concentration for each individual event. To exclude the influence of individual outliers, the 95th percentile was used as

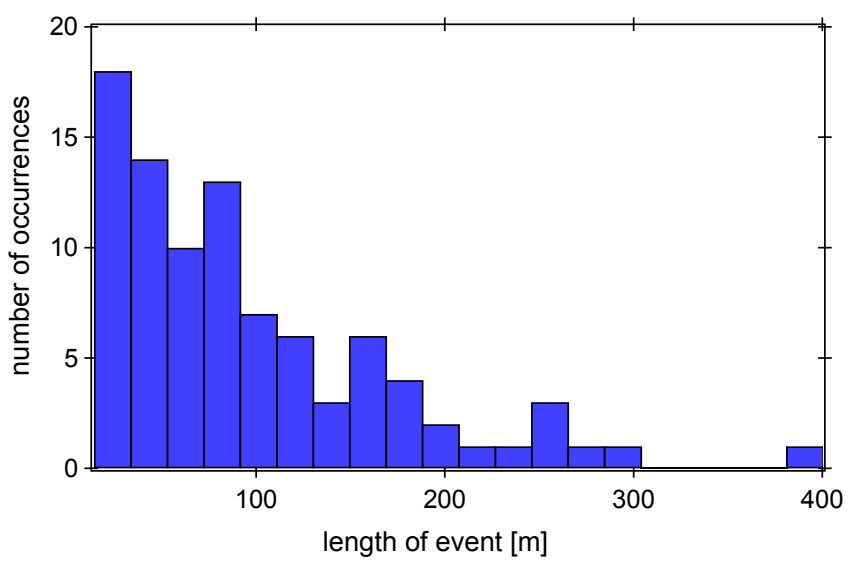

Figure 4. Frequency distribution of the horizontal extent of the observed 91 new particle formation events.

a proxy for the maximum concentration. The maximum observed concentration during CARRIBA was $17000 \mathrm{~cm}^{-3}$, the most frequent maximum concentration occurred between 1000 and $2000 \mathrm{~cm}^{-3}$, and the frequency decreased with increasing number concentration.

\subsection{Correlation of NPF with other variables}

The 91 NPF events occurred at various locations within the cloud layer, varying in length, maximum concentration, shape, and the correlation with other parameters. An interpretation of the nucleation and growth processes inherent in the observed NPF events is complicated for two reasons: (i) the FCPC measures particles $>7 \mathrm{~nm}$, i.e., the nucleation process has occurred some time before the measurement and conditions may have changed, and (ii) there are no measurements 


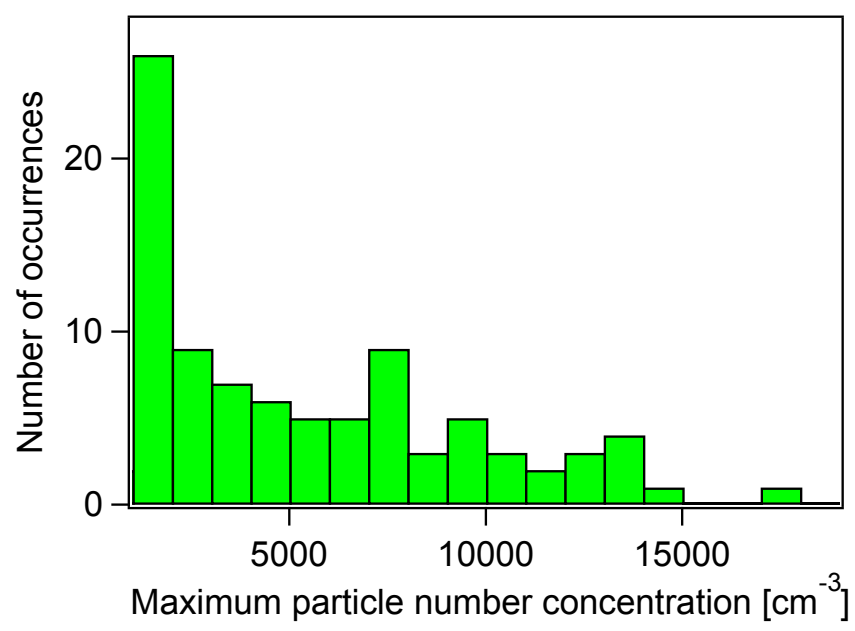

Figure 5. Maximum concentration (95th percentile) of the observed 91 new particle formation events.

of potential precursor gases. However, ACTOS and SMARTHELIOS provide meteorological, microphysical, and upward radiation measurements that can be compared to NPF events for suggestions of correlation. NPF events have been observed at heights between 600 and $2200 \mathrm{~m}$, always within the cloud layer. Interestingly, NPF of a specific measurement flight occurred in a narrow height range, i.e., within 200-300 m. These height ranges were often connected to a change in the number concentration in the vertical profile. Thus, mixing with cleaner air may play a role for the NPF event.

First, we consider correlations of NPF and existence of nearby cloud. During the second CARRIBA campaign in 2011 measurements of the upward spectral irradiance $F_{\lambda}^{\uparrow}$ and cloud-reflected spectral radiance $I_{\lambda}^{\uparrow}$ by SMART-HELIOS are available for all flights. The $I_{\lambda}^{\uparrow}$ data yield the benefit of giving information about the cloud field directly around and below ACTOS. As shown by Werner et al. (2014), comparing spectra sampled over cumuli with those sampled over the ocean surface or the island allows for a clear differentiation between these surfaces via radiance ratios $\mathcal{R}=\frac{I_{\lambda 1}^{\uparrow}}{I_{\lambda 2}^{\uparrow}}$. In this work $\lambda_{1}=720 \mathrm{~nm}$ and $\lambda_{2}=644 \mathrm{~nm}$, resulting in a range indicating cloudy data between $\mathcal{R}=0.6$ and 0.75 , depending on the cloud optical thickness and solar zenith angle. Samples over the ocean show $\mathcal{R}<0.6$, while $\mathcal{R}>1$ for measurements over the island due to the sharp increase in reflectivity of vegetation in the near infrared. The cloud ratio $\mathcal{R}$ yields a reliable estimate of the position of each NPF event relative to the respective cloud field. This is in contrast to in situ-measured LWC data, because, due to the inhomogeneous cloud structure, ACTOS sometimes dipped in and out of cloud tops or entered (left) the cloud later (earlier) than the cloud edge at lower levels. In 2011, 38 of the 44 NPF events were connected to clouds: at the cloud edge, only a few seconds away

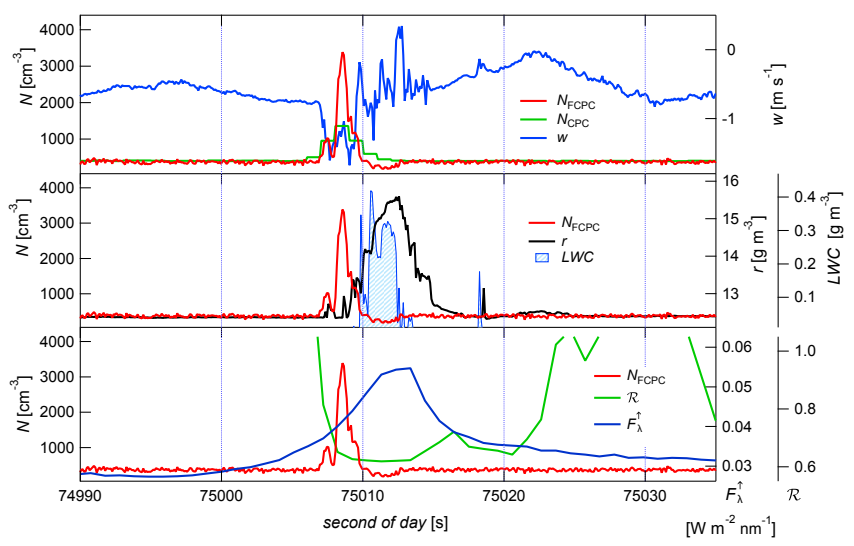

Figure 6. Section of the measurement flight on 14 April 2011 through a cumulus cloud. Presented variables are $w$ (vertical wind speed), $F_{\lambda}^{\uparrow}$ (spectral upward irradiance at $333 \mathrm{~nm}$ ), $r$ (water vapor mixing ratio), $N_{\mathrm{CPC}}$ and $N_{\text {FCPC }}$ (total particle number concentration measured by CPC and FCPC), LWC (liquid water content), and $\mathcal{R}$ (cloud ratio).

from a cumulus or above a cloud. These findings emphasize the strong connection between NPF and cloud boundaries.

Correlations with other measured variables can also be explored. In the following, three representative examples of time series including NPF events are given to illustrate the differences between individual events and potential correlations with other parameters. Presented variables are $w$ (vertical wind speed), $r$ (water vapor mixing ratio), $N$ (total particle number concentration $>7 \mathrm{~nm}$ measured by CPC and FCPC), LWC (liquid water content) to show areas where clouds were present, $F_{\lambda}^{\uparrow}$ (spectral upward irradiance with $\lambda=333 \mathrm{~nm}$ ), and $\mathcal{R}$ (cloud ratio).

Figure 6 shows a NPF case at the edge of a cumulus cloud indicated by LWC $>0$ adjacent to increased values in $N$. Furthermore, $\mathcal{R}$ shows values between 0.6 and 0.7 around this cloud, indicating that ACTOS was measuring above a cloudy area when at the location of the NPF event. Before and after the cloud area, $\mathcal{R}$ increased to values above 1 , indicating measurements over the island without cloud coverage. The total particle number concentration increases from $\approx 300$ to $3500 \mathrm{~cm}^{-3}$ at the cloud edge. The irradiance increases above the cloud by a factor of 2 compared to the region further away from the cloud. The reason is the higher reflectivity of the cloud surface compared to the darker ocean (e.g., Eck et al., 1987). From the cloud ratio it can be concluded that the NPF event occurs above a part of the cloud, i.e., still in the region with enhanced irradiance. Interestingly, the NPF event also corresponds to a downdraft region relative to the cloud. During the NPF, a correlation between $N$ and $r$ is observed.

Figure 7 shows another case of NPF where the enhanced number concentration occurred between two cloud traverses by ACTOS. The 22 April 2014 flight was characterized by 


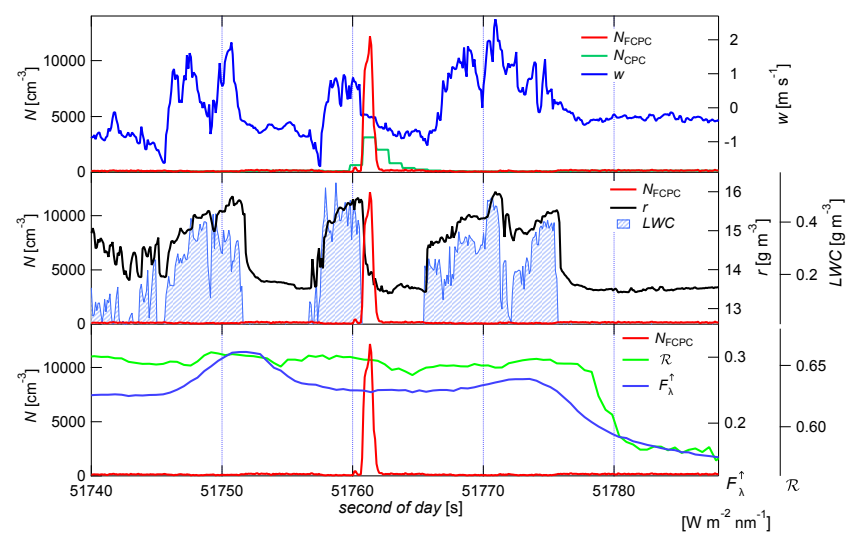

Figure 7. Section of the measurement flight on 22 April 2011; same variables as in Fig. 6.

the lowest particle number concentrations in the cloud-free background during the whole campaign. In the selected section shown in Fig. 7, $N$ varied between 100 and $150 \mathrm{~cm}^{-3}$ and increased to more than $12500 \mathrm{~cm}^{-3}$ during the NPF event. The cloud ratio $\mathcal{R}$ indicates that there was continuous cloud coverage below the measurement height, indicating that the three individual regions of enhanced LWC (sampled in situ by ACTOS) belong to the same cloud. This can occur when ACTOS briefly leaves the cloud top and reenters the cloud a little later. The irradiance is enhanced over the whole region by a factor of 2 compared to the cloud-free background. Here, the NPF occurs in a region where $r$ is still increased compared to background values.

Figure 8 shows a third NPF case observed at the cloud edge as well as within the cloud (entrainment region), where increased particle number concentrations are correlated with a decrease in LWC. The background concentration in the cloud-free regions was around $200 \mathrm{~cm}^{-3}$, and the maximum during the event was around $14000 \mathrm{~cm}^{-3}$. The cloud ratio $\mathcal{R}$ indicates that ACTOS was still above a cloud at $\approx \mathrm{SOD}$ 52 950, i.e., the NPF event occurred above the cloud. Around the observed cloud, $\mathcal{R}$ is fluctuating - i.e., there were some patches of clouds below ACTOS. $F_{\lambda}^{\uparrow}$ has its maximum at the same side of the cloud as $N$, which is also the side reflecting the sun during that flight. $F_{\lambda}^{\uparrow}$ is enhanced by a factor of 1.8 above the background value in the cloud-free environment.

The short NPF event within the cloud is related to a minimum in LWC and occurs in the so-called entrainment region at the cloud edge. This region is characterized by strong small-scale mixing processes leading to evaporation of cloud droplets and therefore a release of potential precursor gases. In combination with turbulent mixing and an increased irradiance, this region provides preferable conditions for NPF. The eddy-like structures in LWC and $N$ illustrate the mixing at the cloud edge nicely and have also been observed in a few more cases. This is in good agreement with results from Clarke et al. (1998), who identified NPF in the outflow re-

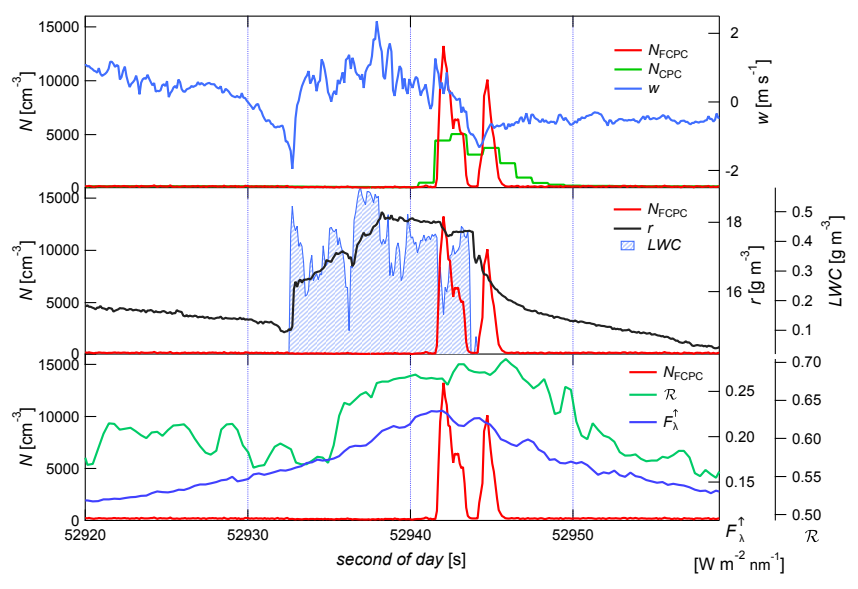

Figure 8. Section of the measurement flight on 23 April 2011; same variables as in Fig. 6.

gions of cumulus clouds driven by enhanced gas concentrations in connection with photochemical activity.

From these examples a connection between NPF events and clouds as regions with increased UV radiation is obvious. During this campaign, 38 out of 44 cases were directly connected to a cloud and an enhanced irradiance was measured. These 38 NPF events in the vicinity of clouds can be additionally divided into two categories, depending on the relative position of ACTOS to the respective cloud and the solar azimuth angle of the sun. Cases with ACTOS between cloud and sun, such as ACTOS approaching and leaving the illuminated side of an individual cumulus, are characterized by increased reflectivity in the UV spectrum (Vant-Hull, 2007). Cases where ACTOS is in a position above a cloud are included in this category, which comprises 32 of the observed $38 \mathrm{NPF}$ events associated with clouds. In the remaining six NPF events the cloud is positioned between ACTOS and the sun, suggesting that ACTOS and SMART-HELIOS were probing in a cloud shadow. Thus, these cases are associated with increased UV radiation, which cannot be explained with the flight direction relative to the cloud-sun axis alone. Here, 3-D effects possibly occur - i.e., the enhanced irradiance is caused by reflections at another part of the cloud. Together with the fact that 38 out of 44 cloud cases are directly connected to an increase in $F_{\lambda}^{\uparrow}$, the UV irradiance seems to be an important factor for new particle production in cloudy regions.

Figure 9 shows the increase in measured irradiance compared to a background value without cloud for the observed cases from April 2011. The increase varies between 1.2 and 3.3 , with a median of 1.78 . This is in good agreement with the study of Weber et al. (2001), who published model simulations to demonstrate that a UV enhancement of a factor of 2 produces reasonable values in $\mathrm{H}_{2} \mathrm{SO}_{4}$ compared with their observations. From ACTOS measurements, no mea- 


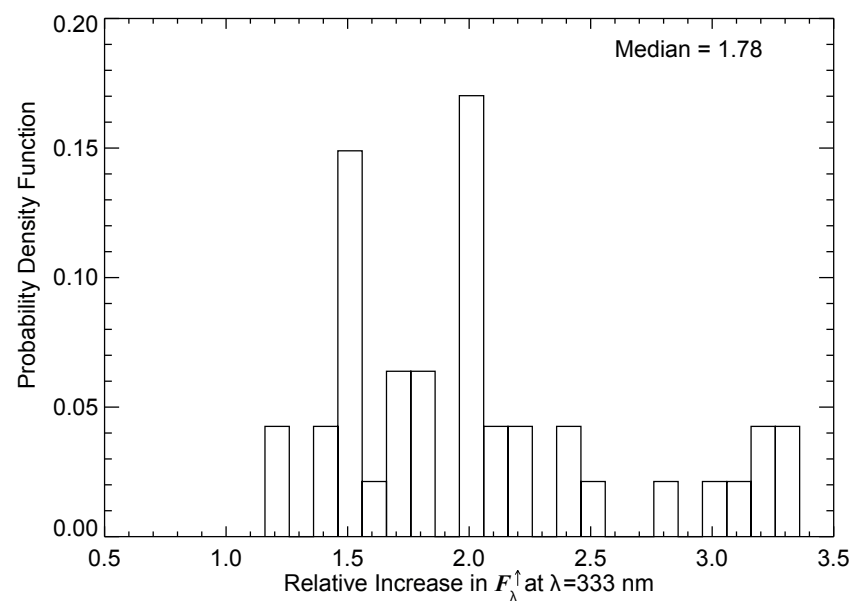

Figure 9. Probability density function of the relative increase in measured irradiance at $333 \mathrm{~nm}$ above the individual cloud compared to a background value without cloud for all NPF events during April 2011.

surements of chemical precursors are available, but $\mathrm{H}_{2} \mathrm{SO}_{4}$ is very likely involved in the nucleation process.

\subsection{Estimated age of particle bursts and implications for particle growth rate}

The observations of NPF events are often characterized by short, burst-like spikes with remarkably sharp edges, implying that they have not become well mixed and diluted by turbulence. At the same time, NPF events are only observable when they have diameters above $7 \mathrm{~nm}$. In this section we use these two observations to estimate a lower bound on the particle growth rate. In order to make a quantitative estimate we select one burst, shown in Fig. 10, which was chosen because it is representative of a typical NPF event.

The total horizontal extent of the burst is approximately $50 \mathrm{~m}$, and we take this as the characteristic dimension of the puff of newly formed particles. A question we can ask is, what is the time required for a spatially localized population of particles to reach this size through turbulent diffusion? The concept of Richardson pair dispersion describes the relative separation of two fluid elements in a turbulent flow for length scales within the inertial subrange, or $\sim 1 \mathrm{~mm}$ to $\sim 100 \mathrm{~m}$. The mean-square separation distance scales as $\left\langle|\delta x|^{2}\right\rangle=g \varepsilon t^{3}$, where $\varepsilon$ is the turbulent kinetic energy dissipation rate and $g$ is the Richardson constant (typically thought to have a value of 0.1 to $\sim 5$ ) (Davidson, 2004). Recent laboratory (Ott and Mann, 2000) and direct numerical simulation (Boffetta and Sokolov, 2002) results suggest $g \approx 0.5$, so while we will consider the full range of possible values, we take this as the most likely value. We do not have any information about the size of the initial burst, but to be conservative in estimates of growth rate we assume that it is at the bottom of the turbulence inertial subrange,

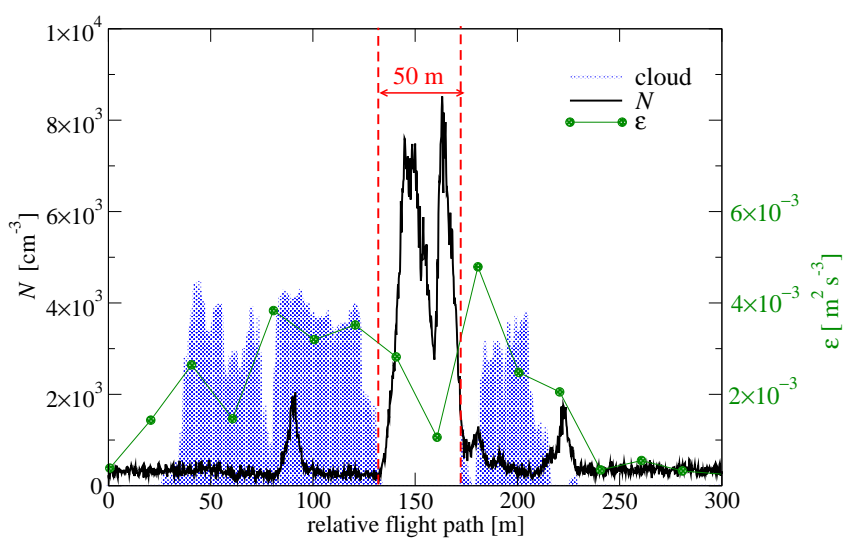

Figure 10. Penetration of a cloud field with a burst of increased number concentrations $N$ of ultrafine particles between two cloud penetrations. The clouds are marked by the blue areas, which represent LWC in arbitrary units. Additionally, the dots show the local energy dissipation rate $\varepsilon$ averaged over a relative flight path of roughly $20 \mathrm{~m}$.

e.g., $\sim 1 \mathrm{~mm}$. In that case, we can obtain an approximate age of the burst as $\mathcal{T}=\left(\mathcal{L}^{2} / g \varepsilon\right)^{1 / 3}$, where $\mathcal{L}=\left\langle|\delta x|^{2}\right\rangle^{1 / 2}$ is the characteristic size of the burst.

The time series of $\varepsilon$ is also shown in Fig. 10, and we use the mean value over the length of the burst, $\varepsilon \approx 2 \times$ $10^{-3} \mathrm{~m}^{2} \mathrm{~s}^{-3}$. Using $\mathcal{L} \approx 50 \mathrm{~m}$, we estimate $\mathcal{T} \approx 136 \mathrm{~s}$. Assuming the particles must reach $d=7 \mathrm{~nm}$ (starting at a cluster size below $1 \mathrm{~nm}$ ) within this time, we can estimate a growth rate of $3 \mathrm{~nm} \mathrm{~min}^{-1}$. Accounting for the range of possible $g$ results in growth rates of 2 to $7 \mathrm{~nm} \mathrm{~min}^{-1}$. For this growth rate, $\approx 1-4 \times 10^{9} \mathrm{~cm}^{-3}$ vapor molecules are needed (see Nieminen et al., 2010). In practice it is very probable that, in addition to sulfuric acid, extremely low volatility organic compounds (ELVOCs) are also involved in the process (see Ehn et al., 2014; Kulmala et al., 1998), because the saturation vapor pressure of condensing vapors should be very small for effective molecular flux into growing newly formed particles, and ELVOCs fulfill these criteria. ELVOC precursors could live inside clouds and convection could transport ELVOC precursors as well as $\mathrm{SO}_{2}$ as a sulfuric acid precursor to cloud edges. The solar radiation outside the cloud and precursors coming from evaporating cloud are able to make photochemical reaction efficient enough to produce ELVOCs. These kinds of growth rates have actually previously been observed at coastal sites like Mace Head (Kulmala et al., 2004).

\section{Conclusions}

This study presents meteorological, aerosol, cloud, and radiation measurements from the CARRIBA campaign that was performed close to the Caribbean island Barbados, in the trade-wind cumulus environment. Ninety-one cases of 
strongly increased particle number concentration caused by NPF were detected in the cloud layer and analyzed to consider event properties and correlations. No NPF events have been observed in the always cloud-free sub-cloud layer, while cumulus clouds were present during all flights in the cloud layer. The available database does not allow for process studies to be performed, but we have sought to identify conditions favoring NPF. Most of the NPF cases were connected to clouds representing an environment with increased irradiance in the ultraviolet (UV) spectral wavelength range. NPF requires photochemical activity for the production of precursor gases. In our case no measurements of gases are available, but the increased UV irradiance at cloud boundaries provides a perfect region for the production of precursors. This could be intensified by turbulent mixing, which is typical for the entrainment regions and therefore for cloud edges. This was also observed for some cases in this study by high fluctuations of thermodynamic variables in the region where NPF occurs. Such small-scale mixing processes may enhance the formation rate of new particles because of strong nonlinearities in the system (Easter and Peters, 1994). From vertical profiles we found variations in particle number concentrations in the height where NPF occurred for the majority of cases; thus mixing with cleaner air may also be one aspect forcing nucleation and growth. Most likely, the connection of the different issues is required: enhanced UV radiation to produce the precursor gases, cloud edges as a region with increased turbulence, and mixing with cleaner air reducing the condensational sink. Radke and Hobbs (1991) observed increased particle number concentrations in the surrounding region of cumulus clouds, which was also characterized by high relative humidities. During CARRIBA, regions with high relative humidities around clouds were also detected by Katzwinkel et al. (2014). In this study, a few cases with correlations between NPF and humidity were also observed, but for other cases no relationship was found.

The presented results agree with earlier publications suggesting that marine clouds play an important role not only as particle sinks due to activation and the following effects on the radiation budget but also as a source of aerosol particles. Cloud edges or cloud tops have been identified as preferred regions for NPF in earlier studies, but these were limited to a few individual cases only. Here, we detected 91 cases demonstrating the relevance for the marine environment. In combination with results from earlier publications (e.g., Clarke et al., 1997, 1998; Perry and Hobbs, 1994; Keil and Wendisch, 2001; Weber et al., 2001), this leads to the conclusion that this phenomenon is not only of regional interest, since it was found in completely different regions of the world. The results are also consistent in general with a modeling study by Kazil et al. (2011) and earlier observations from Petters et al. (2006), where Aitken particles were also connected to NPF near clouds. This was explained by a reduction in the condensation sink due to clouds and precipitation. In addition, cloud updrafts loft dimethyl sulfide from the ocean to the cleaner cloud layer, where it is oxidized to $\mathrm{SO}_{2}$ and $\mathrm{H}_{2} \mathrm{SO}_{4}$. This step requires enhanced radiation and provides precursor gases for NPF.

Another interesting result from this study is the estimate of the lifetime of particle bursts. The mean length of the observed NPF events was $100 \mathrm{~m}$, resulting in a lifetime of less than $300 \mathrm{~s}$. Aerosol instrumentation on ACTOS is restricted to the measurement of particles larger than $7 \mathrm{~nm}$ only; thus these particles grew within this lifetime to detectable sizes, i.e., $7 \mathrm{~nm}$. This implies growth rates of several nanometers per minute, which is in contrast to typical growth rates mainly from ground-based measurements reported in the literature $\left(1-7 \mathrm{~nm} \mathrm{~h}^{-1}\right.$; Kulmala et al., 2004) and is possibly caused by the additional effect of turbulent mixing. However, Dal Maso et al. (2002) reported growth rates up to $200 \mathrm{~nm} \mathrm{~h}^{-1}\left(3.3 \mathrm{~nm} \mathrm{~min}^{-1}\right)$ from a coastal site in Ireland; thus the values deduced here are realistic. However, these growth rates are not possible due to sulfuric acid alone, in particular under clean marine conditions, and it is very probable that extremely low volatility organic compounds (ELVOCs) are involved here (Ehn et al., 2014).

Acknowledgements. We thank the experienced and highly engaged pilots Alwin Vollmer and Milos Kapetanovic for the safe helicopter flights in the Caribbean. We thank Joe Prospero for access to his infrastructure at Ragged Point. We are grateful to Thomas Conrath from TROPOS and Christoph Klaus and Dieter Schell from enviscope $\mathrm{GmbH}$ for their excellent technical support during the campaigns. Thanks also to David Farrel from the Caribbean Institute for Meteorology and Hydrology (CIMH) for logistical support. This work is supported by the Deutsche Forschungsgemeinschaft (SI 1534/3-1, WE 1900/18-1, and WE 2757/1-1/2). R. Shaw acknowledges support from the NSF through grant AGS-1026123.

Edited by: R. Krejci

\section{References}

Birmili, W. and Wiedensohler, A.: New particle formation in the continental boundary layer: Meteorological and gas phase parameter influence, Geophys. Res. Lett., 27, 3325-3328, 2000.

Boffetta, G. and Sokolov, I. M.: Relative dispersion in fully developed turbulence: The Richardson's law and intermittency corrections, Phys. Rev. Lett., 88, 094501, doi:10.1103/PhysRevLett.88.094501, 2002.

Clarke, A. D., Uehara, T., and Porter, J. N.: Atmospheric nuclei and related aerosol fields over the Atlantic: Clean subsiding air and continental pollution during ASTEX, J. Geophys. Res., 102, 25281-25292, 1997.

Clarke, A. D., Varner, J. L., Eisele, F., Mauldin, R. L., Tanner, D., and Litchy, M.: Particle production in the remote marine atmosphere: Cloud outflow and subsidence during ACE 1, J. Geophys. Res., 103, 97JD0987, 16397-16409, 1998.

Covert, D. S., Kapustin, V. N., Quinn, P. K., and Bates, T. S.: New particle formation in the marine boundary layer, J. Geophys. Res., 97, 20581-20589, 1992. 
Craig, L., Moharreri, A., Schanot, A., Rogers, D. C., Anderson, B., and Dhaniyala, S.: Characterizations of Cloud Droplet Shatter Artifacts in two Airborne Aerosol Inlets, Aerosol Sci. Technol., 47, 662-671, 2013.

Dal Maso, M., Kulmala, M., Lehtinen, K. E. J., Mäkelä, J. M., Aalto, P., and O'Dowd, C. D.: Condensation and coagulation sinks and formation of nucleation mode particles in coastal and boreal forest boundary layers, J. Geophys. Res., 107, doi:10.1029/2001JD001053, 2002.

Davidson, P. A.: Turbulence, Oxford University Press, 657 pp., 2004.

Easter, R. C. and Peters, L. K.: Binary homogeneous nucleation: temperature and relative humidity fluctuations, nonlinearity, and aspects of new particle production in the atmosphere, J. Appl. Meteor., 33, 775-784, 1994.

Eck, T. F., Bhartia, P. K., Hwang, P. H., and Stowe, L. L.: Reflectivity of Earth's Surface and Clouds in Ultraviolet from Satellite Observations, J. Geophys. Res., 92, 4287-4296, 1987.

Ehn, M., Thornton, J. A., Kleist, E., Sipilä, M., Junninen, H., Pullinen, I., Springer, M., Rubach, F., Tillmann, R., Lee, B., LopezHilfiker, F., Andres, S., Acir, I.-H., Rissanen, M., Jokinen, T., Schobesberger, S., Kangasluoma, J., Kontkanen, J., Nieminen, T., Kurten, T., Nielsen, L. B., Jørgensen, S., Kjaergaard, H. G., Canagaratna, M., Dal Maso, M., Berndt, T., Petäjä, T., Wahner, A., Kerminen, V.-M., Kulmala, M., Worsnop, D. R., Wildt, J., and Mentel, T. F.: A large source of low-volatility secondary organic aerosol, Nature, 506, 476-479, 2014.

Garrett, T. J., Hobbs, P. V., and Radke, L. F.:High Aitken nucleus concentrations above cloud tops in the Arctic, J. Atmos. Sci., 59, 779-783, 2002.

Hegg, D. A.:Particle-Production in Clouds, Geophys. Res. Lett., 18, 995-998, 1991.

Katzwinkel, J., Siebert, H., Heus, T., and Shaw, R. A.: Measurements of Turbulent Mixing and Subsiding Shells in Trade Wind Cumuli, J. Atmos. Sci., 71, 2810-2822, 2014.

Kazil, J., Wang, H., Feingold, G., Clarke, A. D., Snider, J. R., and Bandy, A. R.: Modeling chemical and aerosol processes in the transition from closed to open cells during VOCALS-REx, Atmos. Chem. Phys., 11, 7491-7514, doi:10.5194/acp-11-74912011, 2011.

Keil, A. and Wendisch, M.: Bursts of Aitken mode and ultrafine particles observed at the top of continental boundary layer clouds, J. Aerosol Sci., 32, 649-660, 2001.

Kulmala, M., Toivonen, A., Mäkelä, J. M., and Laaksonen, A.: Analysis of the growth of nucleation mode particles observed in Boreal forest, Tellus, 50, 449-462, 1998.

Kulmala, M., Vehkamäki, H., Petäjä, T., Dal Maso, M., Lauri, A., Kerminen, V.-M., Birmili, W., and McMurry, P. H.: Formation and growth rates of ultrafine atmospheric particles: a review of observations, J. Aerosol Sci., 35, 143-176, 2004.

Li-Jones, X. and Prospero, J. M.: Variations in the size distributions of non-sea-salt sulfate aerosol in the marine boundary layer at Barbados: Impact of African dust, J. Geophys. Res., 103, 1607316084,, 1998.

Nieminen, T., Lehtinen, K. E. J., and Kulmala, M.: Sub-10 nm particle growth by vapor condensation - effects of vapor molecule size and particle thermal speed, Atmos. Chem. Phys., 10, 97739779, doi:10.5194/acp-10-9773-2010, 2010.
Nuijens, L., Serikov, I., Hirsch, L., Lonitz, K., and Stevens, B.: The distribution and variability of low-level cloud in the North Atlantic trades, Q. J. Roy. Meteorol. Soc., 140, 2364-2374, doi:10.1002/qj.2307, 2014.

Ott, S. and Mann, J.: An experimental investigation of the relative diffusion of particle pairs in three-dimensional turbulent flow, J. Fluid Mech., 422, 207-223, 2000.

Perry, K. D. and Hobbs, P. V.: Further evidence for particle nucleation in clean-air adjacent to marine cumulus clouds, J. Geophys. Res., 99, 94JD01926, 22803-22818, 1994.

Petters, M. D., Snider, J. R., Stevens, B., Vali, G., Faloona, I., and Russell, L. M.: Accumulation mode aerosol, pockets of open cells, and particle nucleation in the remote subtropical Pacific marine boundary layer, J. Geophys. Res.-Atmos., 111, D02206, doi:10.1029/2004JD005694, 2006.

Pfeifer, S., Birmili, W., Schladitz, A., Müller, T., Nowak, A., and Wiedensohler, A.: A fast and easy-to-implement inversion algorithm for mobility particle size spectrometers considering particle number size distribution information outside of the detection range, Atmos. Meas. Tech., 7, 95-105, doi:10.5194/amt-795-2014, 2014.

Radke, L. F. and Hobbs, P. V.: Humidity and particle fields around some small cumulus clouds, J. Atmos. Sci., 48, 1190-1193, 1991.

Saxena, V. K. and Grovenstein, J. D.: The role of clouds in the enhancement of cloud condensation nuclei concentrations, Atmos. Res., 31, 71-89, 1994.

Schmeissner, T., Shaw, R. A., Ditas, J., Stratmann, F., Wendisch, M., and Siebert, H.: Turbulent Mixing in Shallow Trade Wind Cumuli: Dependence on Cloud Life Cycle, J. Atmos. Sci., 72, 1447-1465, 2015.

Shaw, G. E.: Production of condensation nuclei in clean air by nucleation of $\mathrm{H}_{2} \mathrm{SO}_{4}$, Atmos. Environ., 23, 2841-2846, 1989.

Siebert, H., Franke, H., Lehmann, K., Maser, R., Saw, E. W., Shaw, R. A., Schell, D., and Wendisch, M.: Probing fine-scale dynamics and microphysics of clouds with helicopter-borne measurements, B. Am. Meteor. Soc., 87, 1727-1738, 2006.

Siebert, H., Beals, M., Bethke, J., Bierwirth, E., Conrath, T., Dieckmann, K., Ditas, F., Ehrlich, A., Farrell, D., Hartmann, S., Izaguirre, M. A., Katzwinkel, J., Nuijens, L., Roberts, G., Schäfer, M., Shaw, R. A., Schmeissner, T., Serikov, I., Stevens, B., Stratmann, F., Wehner, B., Wendisch, M., Werner, F., and Wex, H.: The fine-scale structure of the trade wind cumuli over Barbados - an introduction to the CARRIBA project, Atmos. Chem. Phys., 13, 10061-10077, doi:10.5194/acp-13-10061-2013, 2013.

Twomey, S.: The Influence of Pollution on the Shortwave Albedo of Clouds, J. Atmos. Sci., 34, 1149-1152, 1977.

Warner, J. and Twomey, S.: The production of cloud nuclei by cane fires and the effect ob cloud droplet concentration, J. Atmos. Sci., 24, 704-706, 1967.

Weber, R. J., Clarke, A. D., Litchy, M., Li, J., Kok, G., Schillawski, R. D., and McMurry, P. H.: Spurious aerosol measurements when sampling from aircraft in the vicinity of clouds, J. Geophys. Res., 103, 28337-28346, 1998.

Weber, R. J., Chen, G., Davis, D. D., Mauldin III, R. L., Tanner, D. J., Eisele, F. L., Clarke, A. D., Thornton, D. C., and Bandy, A. R.: Measurements of enhanced $\mathrm{H} 2 \mathrm{SO} 4$ and $3-4 \mathrm{~nm}$ particles near a frontal cloud during First Aerosol Characterization Experiment (ACE 1), J. Geophys. Res., 106, 24107-24117, 2001. 
Wehner, B., Siebert, H., Ansmann, A., Ditas, F., Seifert, P., Stratmann, F., Wiedensohler, A., Apituley, A., Shaw, R. A., Manninen, H. E., and Kulmala, M.: Observations of turbulence-induced new particle formation in the residual layer, Atmos. Chem. Phys., 10, 4319-4330, doi:10.5194/acp-10-4319-2010, 2010.

Wehner, B., Siebert, H., Hermann, M., Ditas, F., and Wiedensohler, A.: Characterisation of a new Fast CPC and its application for atmospheric particle measurements, Atmos. Meas. Tech., 4, 823833, doi:10.5194/amt-4-823-2011, 2011.
Werner, F., Siebert, H., Pilewskie, P., Schmeissner, T., Shaw, R. A., and Wendisch, M.: New airborne retrieval approach for trade wind cumulus properties under overlying cirrus, J. Geophys.Res.-Atmos., 118, 3634-3649, doi:10.1002/jgrd.50334, 2013.

Werner, F., Ditas, F., Siebert, H., Simmel, M., Wehner, B., Pilewskie, P., Schmeissner, T., Shaw, R. A., Hartmann, S., Wex, H., Roberts, G. C., and Wendisch, M.: Twomey effect observed from collocated microphysical and remote sensing measurements over shallow cumulus, J. Geophys. Res., 119, 1534-1545, doi:10.1002/2013JD020131, 2014. 